\title{
Abusive Head Trauma in Turkey and Impact of Multidisciplinary Team Establishment Efforts on Case Finding and Management: Preliminary Findings
}

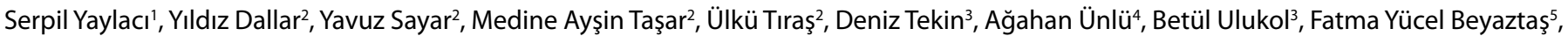

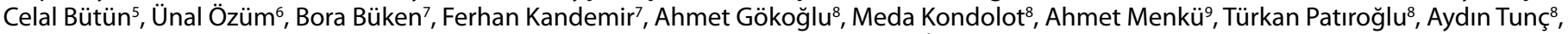
Fatih Yağmur ${ }^{10}$, Ali Yıkılmaz ${ }^{11}$, Taner Akar ${ }^{12}$, Ufuk Beyazova ${ }^{13}$, Bülent Değirmenci ${ }^{12}$, Elvan İşeri'14, Figen Şahin ${ }^{13}$, Aysun Baransel Isır ${ }^{15}$, Ayşe Gül Bilen ${ }^{15}$, Resmiye Oral ${ }^{16}$, Nurperi Gazioğlu ${ }^{17}$, Yasemin Balci ${ }^{18}$, Mesut Eryürük ${ }^{18}$, Feyza Karagöz ${ }^{19}$

'Department of Emergency, Acıbadem University, İstanbul, Turkey

${ }^{2}$ Department of Pediatrics, Ministry of Health Ankara Hospital, Ankara, Turkey

${ }^{3}$ Department of Pediatrics, Ankara University School of Medicine, Ankara, Turkey

${ }^{4}$ Department of Neurosurgery, Ankara University School of Medicine, Ankara, Turkey

${ }^{5}$ Department of Forensic Medicine, Cumhuriyet University School of Medicine, Sivas, Turkey

${ }^{6}$ Department of Neurosurgery, Cumhuriyet University School of Medicine, Sivas, Turkey

'Department of Forensic Medicine, Düzce University School of Medicine, Bolu, Turkey

${ }^{8}$ Department of Pediatrics, Erciyes University School of Medicine, Kayseri, Turkey

${ }^{9}$ Department of Neurosurgery, Erciyes University School of Medicine, Kayseri, Turkey

${ }^{10}$ Department of Forensic Medicine, Erciyes University School of Medicine, Kayseri, Turkey

"Department of Radiology, Erciyes University School of Medicine, Kayseri, Turkey

${ }^{12}$ Department of Forensic Medicine, Gazi University School of Medicine, Ankara, Turkey

${ }^{13}$ Department of Pediatrics, Gazi University School of Medicine, Ankara, Turkey

${ }^{14}$ Department of Psychiatry, Gazi University School of Medicine, Ankara, Turkey

${ }^{15}$ Department of Forensic Medicine, Gaziantep University and Children's Hospital, Gaziantep, Turkey

${ }^{16}$ Department of Pediatrics, lowa University, lowa City, USA

${ }^{17}$ Department of Neurosurgery, İstanbul University İstanbul School of Medicine, İstanbul, Turkey

${ }^{18}$ Department of Forensic Medicine, Osmangazi University School of Medicine, Eskişehir, Turkey

${ }^{19}$ Department of Neurosurgery, Vakıf Gureba Hospital, İstanbul, Turkey

\section{Abstract}

Aim: Abusive head trauma (AHT) is the most common cause of death as the result of child abuse. A task force is planned to provide training on AHT to professionals in different disciplines on clinical presentation, diagnostic workup, and organization of multidisciplinary evaluation at the hospital and community levels. This study reports on the preliminary findings of the pre-intervention phase of a larger study.

Materials and Methods: This is a descriptive, retrospective study exploring the rates of documentation of relevant data in charts, including risk factors for abuse, family demographics, completeness of diagnostic workup, and case finding.

Results: Overall, 345 cases were found in hospital databases that were eligible for the retrospective study from 10 participating hospitals. In total, 305 cases (88.4\%) were younger than 2 years of age. The most common documented risk factors were low parental education level in 82 families (23.8\%), more than three children under 7 years of age in 76 families (22.0\%), and bad child temper in 16 families (4.6\%), among others. The rate of complete diagnostic workup in hospitals with a multidisciplinary team (MDT) $(25.7 \%)$ was statistically significantly higher than in hospitals without an MDT $(2.9 \%)(p=0.001)$. Etiology was identified as inflicted in 78 cases (22.6\%), possibly inflicted in $24(7.0 \%)$, undetermined in $79(22.9 \%)$, and accidental in $164(47.5 \%)$ by the researchers, compared to only three cases $(0.8 \%)$ diagnosed as inflicted by the treating physicians $(p<0.0001)$. In two of the three cases, the perpetrator was convicted; in one, the prosecutor closed the case without a trial on the basis of "no confession" despite the death of the child and medical evidence.

Conclusion: Clinicians' knowledge of the diagnosis of AHT should be increased to improve case finding, which will allow determination of more accurate incidence/prevalence. This can be accomplished via the establishment of an MDT in teaching hospitals as well as staff training on how to recognize suspicious cases, how to utilize MDT services, and how to report and manage cases on a community level multidisciplinary basis. (Eurasian J Emerg Med 2016; 15: 24-9)

Keywords: Abusive head trauma, multidisciplinary team, diagnostic workup

Correspondence to: Serpil Yaylacı e-mail: serpilyaylaci@hotmail.com

Received: 17.02.2016 Accepted: 23.02.2016

(C) Copyright 2016 by Emergency Physicians Association of Turkey - Available online at www.eajem.com

DOI: $10.5152 /$ eajem.2016.52386 


\section{Introduction}

Child abuse and neglect is recognized globally as an important problem from public health, child protection, and child rights perspectives. Physical abuse is a form of child abuse that is highly prevalent worldwide. Violence against children is present in almost all aspects of a child's life: in their home, in school, on the street, at work, in institutions, and in detention centers (1). Children are beaten, tortured, sexually assaulted, or even murdered by the very individuals responsible for their care, and many forms of violence are often viewed as socially acceptable in many societies. The World Report on Violence Against Children provides a global picture of violence against children and proposes recommendations to prevent and respond to this issue. This study reported an estimated homicide rate of 2.04 per 100,000 population in 0-4-year-old males and females in all regions of the United Nations and at all income levels (2).

Abusive head trauma (AHT) is a subcategory of physical abuse. Incidence of AHT is based on limited studies and hospital records; thus, it makes up a small portion of all abuse cases. Keenan et al. studied population-based incidence of AHT in the USA and reported that the incidence of inflicted traumatic brain injury in the first 2 years of life was 17.0 per 100,000 person-years. Infants in the first year of life had a higher incidence than children in the second year of life (29.7 vs. 3.8 per 100,000 person-years) (3). However, this incidence is believed to be much higher than reported because milder forms of AHT may resolve without a hospital visit (4).

Population studies that have studied the use of shaking as a child discipline method propose that actual incidence of AHT in societies where shaking is part of child discipline may range anywhere from $0 \%$ to as high as $63.0 \%$. It is concerning that in this study, $\geq 20 \%$ of mothers in 9 communities from 19 communities in Brazil, Chile, Egypt, India, the Philippines, and the United States admitted to shaking children younger than 2 years (5).

Child abuse and neglect is a fairly new clinical field in the Turkish medical community. Many university hospitals have established multidisciplinary teams (MDT) to implement the clinical practice of child protection in Turkey from 1996 on $(6,7)$. Most of these teams have been collaborating with the University of lowa Child Protection Program to improve their practice. This collaboration and the implementation of multiple teams across the country improved the response to sexual abuse significantly over the first decade. However, AHT has remained only occasionally recognized, with a handful of cases reported in the literature in Turkey (8-12).

Recognizing this low level of professional awareness, an AHT Task Force was established in Turkey in 2008. The task force planned to provide training on $\mathrm{AHT}$ to professionals in pediatrics, forensic medicine, neurosurgery, ophthalmology, radiology, emergency medicine, social work, law enforcement, and prosecution on biomechanics, clinical presentation, diagnostic workup, and organization of multidisciplinary evaluation at the hospital and community levels. This study reports on the preliminary findings of the retrospective pre-intervention phase of the larger study.

\section{Materials and Methods}

This is a descriptive, retrospective study exploring the rates of documentation of relevant data in charts, including risk factors for abuse and neglect and family demographics, as these parameters may help physicians with diagnostic workup for AHT and with case-finding. An invitation was extended to 20 teaching hospitals to participate in this study, 10 of which agreed.

Pre-training data from 10 hospitals are included in this report, namely from Gaziantep Children's Hospital, Ankara University, Vakıf Gureba University, Cumhuriyet University, Düzce University, Gazi University, Gaziantep University, Erciyes University, Osmangazi University, and the Ministry of Health Ankara Hospital. Seven of these hospitals are university hospitals, and the rest are teaching hospitals within the network of the Turkish Ministry of Health. Three of the ten hospitals had a hospital-based MDT. No hospital MDT had a neurosurgeon as a team member. The number of head trauma cases enrolled in this study from each hospital and their pediatric emergency department load per year are shown in Table 1. After obtaining permission from the hospital administrations, all pediatric patients admitted for head trauma to the emergency departments during 2008 that met the inclusion criteria as listed below were included in the study.

Inclusion criteria: a) Age: less than 36 months; b) Head CT and/ or MRI shows acute SDH (with or without chronic SDH), subarachnoid hemorrhage (SAH), epidural hematoma (EDH), skull fracture, or subgaleal hematoma (SGH) with or without; and c) neurologic compromise (concussion, brain edema, brain infarction, brain contusion, brain laceration, coma, seizures, etc.).

Exclusion criteria: a) Children with coagulopathy due to a known medical condition such as hemophilia, Von Willebrand disease, immune thrombocytopenic purpura, and disseminated intravascular coagulopathy; b) children older than 3 years of age; c) newborns who developed an intracranial hemorrhage while in the newborn unit; and d) secondary intracranial hemorrhage that developed in the hospital during treatment for meningitis/encephalitis/ tumor, neurosurgical intervention for non-trauma related causes, etc.

Study data were obtained from the hospital files and judicial records by researchers. The etiology of head trauma in children under three years of age was explored using a scale categorized as accidental, undetermined, possibly inflicted, or inflicted. The algorithm used

Table 1. The number of head trauma cases enrolled from each participating hospital and their pediatric emergency department load per year

\begin{tabular}{|c|c|c|c|c|c|c|c|c|c|c|}
\hline $\begin{array}{l}\text { Hospital } \\
\text { (n)* }\end{array}$ & $\begin{array}{c}\text { GCH } \\
(98)\end{array}$ & $\begin{array}{c}A U \\
(31)\end{array}$ & $\begin{array}{l}\text { VGU } \\
\text { (79) }\end{array}$ & $\begin{array}{c}\text { CU } \\
(39)\end{array}$ & $\begin{array}{l}\text { DU } \\
(3)\end{array}$ & $\begin{array}{c}\text { GU } \\
(17)\end{array}$ & $\begin{array}{l}\text { GAU } \\
(20)\end{array}$ & $\begin{array}{l}\text { EU } \\
(20)\end{array}$ & $\begin{array}{c}\text { OGU } \\
(5)\end{array}$ & $\begin{array}{c}\text { MAH } \\
(33)\end{array}$ \\
\hline $\begin{array}{l}\text { Pediatric emergency } \\
\text { department patient } \\
\text { load per year }\end{array}$ & 183,000 & 43,000 & 146,000 & 10,000 & 18,000 & 39,500 & 28,000 & 57,500 & 29,000 & 38,500 \\
\hline
\end{tabular}




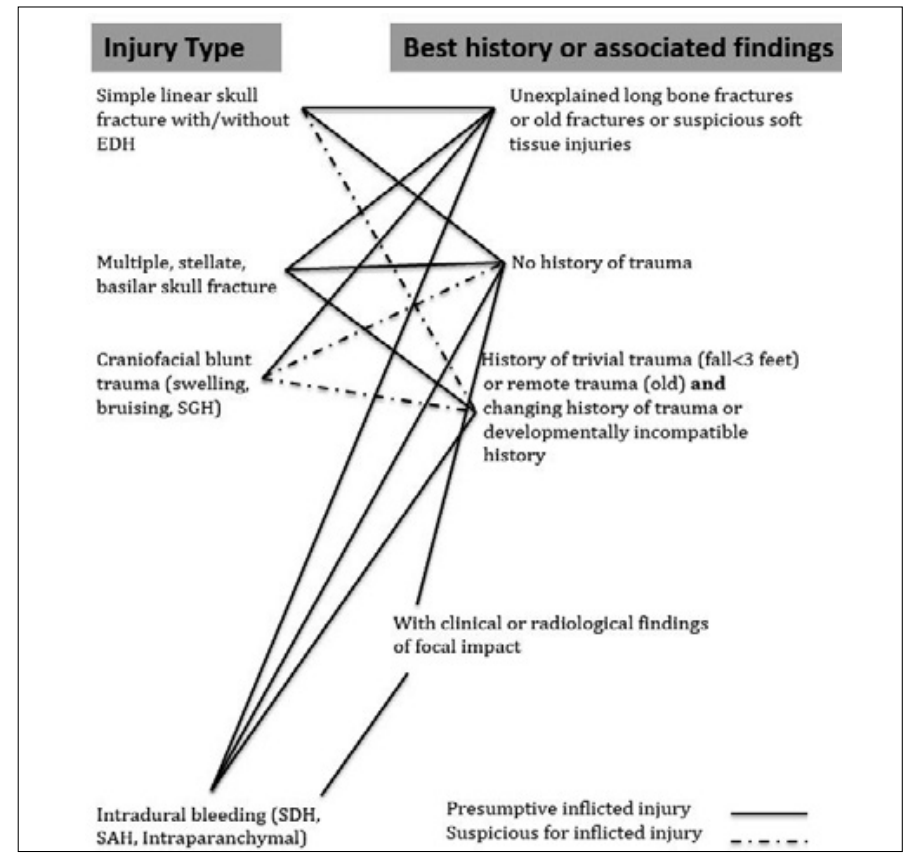

Figure 1. Algorithm to determine the etiology of head trauma in young children (13) for this purpose is depicted in Figure 1 (13). Cases that were designated to the "undetermined" category had one or more of the below characteristics:

1) Inadequate information that prohibited the utilization of the algorithm

2) Adequate information for the use of the algorithm, but the child is an infant ( $<12$ months of age)

3) Imaging findings are inconsistent with presenting symptoms and length of stay (comatose child or child whose hospital stay is longer than 3 days without fatality, with benign imaging findings reported).

This is a descriptive study exploring the documentation of relevant data in the charts, risk factors for abuse and neglect documented in the charts, demographic characteristics of families in which AHT occurs, rate of case findings, completeness of diagnostic workup, and post-hospital case management.

Nine risk factors were low parental education level, more than three children under 7 years of age in the family, bad child temper, child physical illness, child developmental delay, parental physical illness and admission to the hospital with a similar condition for each, domestic violence, previous abuse history, and sibling abuse history. When there was at least one risk factor, we defined that risk factor $(+)$; if there was more than one risk factor, we measured mean $\pm S D$ (range) by hospital.

Table 2. The demographic data and distribution of risk factors by hospitals

\begin{tabular}{|c|c|c|c|c|}
\hline Hospital (n) & $\begin{array}{l}\text { Age (month) } \\
\text { Mean } \pm S D\end{array}$ & $\begin{array}{c}\text { Gender } \\
\text { Male (\%)* }\end{array}$ & $\begin{array}{c}\text { Risk factor (+) } \\
\text { n (\%)* }\end{array}$ & $\begin{array}{c}\text { of risk factors } \\
\text { Mean } \pm S D \text { (range) }\end{array}$ \\
\hline GCH (98) & $19.2 \pm 10.1$ & $56(57.1)$ & 91 (92.8) & $2.7 \pm 1.3(1-5)$ \\
\hline VGU (79) & $13.9 \pm 7.3$ & $45(56.9)$ & 75 (94.9) & $1.8 \pm 1.1(1-6)$ \\
\hline CU (39) & $20.5 \pm 10.5$ & $18(47.4)$ & $22(57.9)$ & $1.6 \pm 1.3(1-7)$ \\
\hline GU (17) & $17.4 \pm 8.6$ & $7(43.7)$ & $14(87.5)$ & $2.6 \pm 1.3(1-4)$ \\
\hline GAU (20) & $9.1 \pm 6.9$ & $14(70)$ & $7(35)$ & $1.1 \pm 0.4(1-2)$ \\
\hline EU (20) & $14.0 \pm 8.3$ & $11(57.9)$ & $16(84.2)$ & $2.1 \pm 1.2(1-5)$ \\
\hline OGU (5) & $14.4 \pm 5.0$ & $1(20)$ & $2(40)$ & $1.5 \pm 0.7(1-2)$ \\
\hline
\end{tabular}

*Percentages were calculated horizontally. GCH: Gaziantep Children's Hospital; AU: Ankara University; VGU: Vakif Gureba University; CU: Cumhuriyet University; DU: Düzce University; GU: Gazi University; GAU: Gaziantep University; EU: Erciyes University; OGU: Osmangazi University; MAH: Ministry of Health Ankara Hospital

Table 3. Reported abusive head trauma cases

\begin{tabular}{|l|c|c|c|c|c|}
\hline Case & Hospital & Sex & Age (month) & Offender & Comments \\
\hline 1 & CU & Female & 6 & Father & $\begin{array}{c}\text { Offender convicted, } \\
\text { GCS=3, witnessed by mother, } \\
\text { child recovered with handicaps }\end{array}$ \\
\hline 2 & EU & Female & 24 & Stepmother & $\begin{array}{c}\text { Offender convicted, sentenced } \\
\text { to life imprisonment, GCS=3, no } \\
\text { confession, no witness, child died }\end{array}$ \\
\hline 3 & GU & Female & 9 & $?$ & $\begin{array}{c}\text { Not tried, prosecutor closed case, } \\
\text { GCS=3, no confession, child died }\end{array}$ \\
\hline
\end{tabular}

GCS: Glasgow Coma Scale; CU: Cumhuriyet University; EU: Erciyes University; GU: Gazi University 
Table 4. Post-medical management

\begin{tabular}{|c|c|c|c|c|}
\hline Hospital & MDT & $\begin{array}{l}\text { Filed to police } \\
\text { n (\%) }\end{array}$ & $\begin{array}{l}\text { Filed to CPS } \\
\text { n (\%) }\end{array}$ & $\begin{array}{l}\text { Removed from home } \\
\text { n (\%) }\end{array}$ \\
\hline $\mathrm{GCH}(98)$ & - & 98 (100) & $98(100)$ & - \\
\hline $\mathrm{AU}(31)$ & + & $31(100)$ & - & - \\
\hline VGU (79) & - & $22(27.8)$ & - & - \\
\hline CU (39) & - & 37 (97.3) & $1(2.6)$ & $1(2.6)$ \\
\hline DU (3) & - & $3(100)$ & - & $1(33.3)$ \\
\hline GU (17) & + & $16(100)$ & $16(100)$ & - \\
\hline GAU (20) & - & $1(5.0)$ & - & - \\
\hline EU (20) & + & 7 (36.8) & $6(31.5)$ & - \\
\hline OGU (5) & - & - & - & - \\
\hline MAH (33) & - & $29(87.8)$ & - & - \\
\hline Total (345) & & 244 (70.7) & $121(35.2)$ & $2(0.6)$ \\
\hline
\end{tabular}

\section{Statistical analysis}

All data obtained in the study were recorded in a database and analyzed using the Statistical Package for the Social Sciences (SPSS Inc; Chicago, IL, USA) for Windows, Version 17. Numerical variables were identified as mean and standard deviation (SD), whereas categorical variables were given as frequency $(n)$ and percentage. The chi-square test was used for categorical comparisons. The association between the rate of both skeletal survey and retinal exam practice and the presence of an MDT at a hospital was analyzed via the chisquare test.

\section{Results}

Overall, 345 cases that were eligible for this study were found in hospital databases (Table 1). In total, 305 cases (88.4\%) were younger than 2 years of age. In addition, $56 \%$ of the children were male, and the mean age was 16.1 \pm 9.3 months (range: 1-36 months) (Table 2).

The most common documented risk factors were low parental education level in 82 cases (23.8\%), more than three children under 7 years of age in the family in 76 (22.0\%), bad child temper in 16 (4.6\%), child physical illness in 10 (2.9\%), child developmental delay in 8 (2.3\%), parental physical illness and admission to the hospital with a similar condition for each in 7 (2.0\%), domestic violence in 4 (1.2\%), previous child abuse history in $2(0.6 \%)$, and sibling abuse history in $1(0.3 \%)$. The rates of risk factors by hospital are given in (Table 2 ).

In total, 299 (86.7\%) cases presented with a history of trauma on admission; the rest presented with no history of trauma. The Glasgow coma scale (GCS) was not documented in 67 (19.4\%) cases, was less than 6 in 33 (9.6\%), was between 7 and 12 in 138 (40.0\%), and was between 13 and 15 in 107 (31.0\%). Etiology was identified as inflicted in 78 cases (22.6\%), possibly inflicted in 24 (7.0\%), undetermined in 79 (22.9\%), and accidental in 164 (47.5\%) by the researchers. The difference between the GCS scores among the four etiology groups, when available, was statistically significant $(p<0.001)$ : When GCS was 6 and less, $30.3 \%$ of cases were assigned an etiology code of inflicted compared to $13.8 \%$ for GCS 7-12 and
$31.8 \%$ for GCS $13-15$. The length of stay was $5.7+10.4$ days in the overall group (range 0-123 days).

In inflicted cases, there was no reported history of trauma in 4 (5.1\%), reported history of trauma in $21(26.9 \%)$, and unknown history of trauma in $53(67.9 \%)$ of the cases. In accidental cases, there was no reported history of trauma in $3(1.8 \%)$, reported history of trauma in $87(53.0 \%)$, and unknown history of trauma in $74(45.1 \%)$ of the cases.

The most common chief complaints for the younger than two years age group on presentation were lethargy and change in consciousness in 80 cases (26.2\%), scalp swelling, bruising, and bleeding in 49 (16.1\%), (no complaint) fall from height in 39 (12.8\%), cardio-respiratory arrest in $32(10.5 \%)$, apnea in 29 (9.5\%), seizures in $26(8.5 \%)$, vomiting in $18(5.9 \%)$, a combination of the above in 16 $(5.2 \%)$, irritability in $5(1.6 \%)$, otorhagia in $5(1.6 \%)$, periorbital hematoma in $3(1.0 \%)$, hypotonia in $2(0.7 \%)$, and other in $1(0.3 \%)$. There was a combination of altered mental status, abnormal respiratory status, and seizures in 183/305 (60.0\%) cases.

Diagnostic workup, including skeletal survey and ophthalmology exam in children under 2 years of age, in which age group these studies are indicated, was complete in 25 cases (7.2\%). Totally, 132 cases (38.2\%) had a skeletal survey (20 complete, 112 partial) but not a retinal exam. Seven (2.0\%) cases had a retinal exam but not a skeletal survey. Totally, 183 patients had altered mental status, abnormal respiratory status, and seizures. Of 305 cases, only 18 (9.8\%) had a full workup including both skeletal survey and retinal exam.

The rate of diagnostic workup, including both skeletal survey and retinal exam, in hospitals with a MDT (25.7\%) was statistically significantly higher than in hospitals without a MDT $(2.9 \%)(p=0.001)$. Three cases $(0.8 \%)$ were diagnosed as inflicted by the treating physicians. Because 78 cases in this study were assessed to be inflicted, $3.4 \%$ of AHT cases were recognized as such by the treating teams; hence, the rate of missed diagnosis was $96.6 \%$. A low rate of diagnostic workup including both skeletal survey and retinal exam was associated with the absence of an MDT. In two of the three cases, the perpetrator was convicted; in one, the prosecutor closed the case without a trial on the basis of "no confession" despite the death of the child and medical evidence (Table 3 ). 
A forensic report was filed with the police in 244 cases $(70.7 \%)$ because all juicidal injuries in Turkey presenting to the emergency department are expected to be routinely reported to police; however, Child Protective Services (CPS) was informed in only 121 cases (35.2\%). At the end of assessment, of the 244 children reported to police, $2(0.8 \%)$ were seperated from their family and placed in state custody. A multidisciplinary team approach was established in 3/10 (30.0\%) of the hospitals (Table 4).

\section{Discussion}

This study revealed that multidisciplinary management of pediatric head injury cases under 3 years of age with a consideration of AHT in differential diagnosis is rarely performed at teaching hospitals in Turkey. Only three of the participating hospitals of this study practiced a multidisciplinary approach. As a result, pediatric head injury cases are not optimally managed from diagnostic workup, etiologic assessment, and post-hospital management perspectives. This study supported the hypothesis that very few pediatric head injury cases are assessed to look for AHT, with subsequent high rates of missed diagnosis (96.2\%).

To increase diagnostic ability, a through family interview is of paramount importance to reveal associated risk factors in cases presenting with traumatic injuries. Once suspected, including AHT in differential diagnosis would guide physicians to include retinal examination, skeletal survey, and head CT in diagnostic workup, which will provide all potential data to either confirm or rule out AHT. Especially, emergency department doctors should ascertain and document risk factors for AHT in suspected cases. Assessment of a number of risk factors may permit health professionals to identify parents and children who are at a high risk for child maltreatment, facilitating appropriate implementation of prevention and treatment interventions (14). A study investigating the risk factors for AHT in the Netherlands reported that $40 \%$ of the parents had low educational levels (15). In a military cohort study, parental risk factors included younger maternal age, lower sponsor rank or economical status, and current maternal military service (16). Hennes et al. (17) reported risk factors for AHT as single-parent families, mothers younger than 18 years of age, mothers with low education, mothers who did not have prenatal care, and families with a low socioeconomic status.

There are some characteristics of the child that appear to increase the probability of AHT, such as child's age younger than 1 year, male gender, and premature birth or low birth weight (17). The baby's normal pattern of crying has been reported as the main trigger for the occurence of AHT (18). In the current study, the most common risk factors were determined to be families with low parental education level (23.8\%) and having a maximum of three children under seven years of age (22\%). However, in the majority of cases, risk factors were not explored and documented, impairing the physicians' ability to establish an accurate differential diagnostic list and leading to low rates of appropriate workup and case finding.

Abusive head trauma is the most common cause of death as the result of child abuse. Infants frequently present with nonspecific clinical features without any history of trauma. A groundbreaking study reported that even at a prestigious institution in the USA, as many as $30 \%$ of children with AHT may be misdiagnosed at the initial evaluation (19). As shown above, the case series reported here revealed that the absence of a history of trauma was important based on final etiology: In inflicted cases, there was no reported history of trauma in $4(5.1 \%)$ of the cases compared to $3(1.8 \%)$ in accidental cases.

Ascertainment of AHT diagnosis is critical to prevent a potentially fatal recurrence. In order to prevent this form of child abuse and potential fatalities, physicians should recognize that AHT presents with acute encephalopathy, anywhere from somnolence to coma; acute or chronic subdural hematoma with or without subarachnoid hemorrhages; and retinal hemorrhages occurring in the context of an inappropriate, inconsistent, or absent trauma history (20). In this study, of the 78 cases that were assessed to be inflicted, 4 had no history of trauma and 21 had consistent trauma history.

Retinal hemorrhages are noted in $60 \%-85 \%$ of children with AHT in a retrospective series (21). Dilated retinal examinations in infants and children with nonspecific symptoms of illness that raise concern for intracranial processes could increase the recognition of retinal hemorrhages (13). Children under two years of age with suspected AHT should have a fundoscopic examination, preferably by an ophthalmologist, to identify retinal hemorrhages and other eye injuries. Non-ophthalmologists may have difficulty performing an adequate examination and thereby fail to identify injuries that, although not pathognomonic, suggest inflicted injury (22). To accomplish this, every MDT should have an ophthalmologist involved in the team. In this study, evaluation of the retina of the under 2-yearold group was made in extremely few cases (8.2\%) that it points to the absence of a structured diagnostic assessment of these cases in the teaching hospitals of Turkey. Extensive intraocular hemorrhage involving multiple layers, extending to the periphery of the eye globe, and presenting with retinal detachment/macular folds in young infants in the setting of acute brain injury and in the absence of a history of severe accidental trauma or underlying medical cause must be considered to be nonaccidental injury until proven otherwise (23).

Distinguishing AHT in young children from other diseases by symptoms is difficult in practice. In one study, physicians missed the diagnosis on initial presentation in one third of cases, and this resulted in repeated trauma, increased morbidity, and death (24). Jenny et al. (19) reported that four factors increased the likelihood of correct diagnosis of $\mathrm{AHT}$, including abnormal respiratory status (by sevenfold), presence of seizures (by sevenfold), presence of facial and/or scalp injury (by fivefold), and parents not living together (by twofold). However, if a child had normal respiration, had no seizures, no facial or scalp injury, and came from an intact family, the probability that AHT would be recognized was less than 1 in 5 (19). In the current study, even when the patients had altered mental status, abnormal respiratory status, and seizures, only $9.8 \%$ of 183 such cases had a full workup, indicating the low level of diagnostic care these cases received in the participating hospitals.

Previous studies have reported that over $60 \%$ of victims of AHT may have a history and/or clinical evidence of previous child abuse. Physicians assessing children, especially infants, should be alert to indicators of AHT to recognize abuse early on. Including AHT in the differential diagnostic list and taking appropriate steps to rule out or confirm the diagnosis are of paramount importance in establishing child protective services and preventing further abuse and neglect that may at times be fatal (9). In this study, $70.7 \%$ of cases were reported to police Because all juicidal trauma cases presenting to the emergency department are by law expected to be reported to law enforcement. However, because professional training of both police forces and prosecutors is not optimal and most trauma cases require social services rather than criminal litigation, most of these reports are 
dismissed with little attention paid to the details $(6,7)$. Child protective services staff are also suboptimally trained on AHT specifically.

Publications on AHT have skyrocketed worldwide and in Turkey alike during the last decades. This can be explained by increased awareness of this issue $(25,26)$. Clinicians' knowledge on the diagnosis of AHT should be increased to improve case finding, which will allow a more accurate determination of incidence (6). This can be accomplished via establishment of MDT in teaching hospitals, as well as staff training on how to recognize suspicious cases, how to utilize MDT services, and how to report and manage cases on a community based multidisciplinary basis.

\section{Study limitations}

This study has several limitations that could impact both the generalizability and interpretability of the findings. Firstly, data were obtained retrospectively. In addition, voluntary hospitals were included in the study; therefore, it can neither be claimed that the study findings reflect the facts on relevant practices in non-participating hospitals nor do they represent the practices in community hospitals.

\section{Conclusion}

According to our results, a prospective study should be conducted involving the close to 30 MDTs established in Turkey in teaching hospitals during the last decade. These teams should develop a structured protocol on how to recognize, assess, and manage AHT; train hospital staff at large who might come into contact with suspected AHT cases, including emergency department, pediatrics, neurosurgery, surgery, radiology, ophthalmology, pathology, and nursing staff; develop a child protection consultation system; and focus on prevention efforts. Thus, each child head trauma may be assessed appropriately, leading to increased case finding and prevention of such abuse. Prevention strategies should include parental education on child development, especially on the infant's crying pattern.

Ethics Committee Approval: Ethics committee approval for this study was excluded because it is a retrospective study.

Informed Consent: Patient consent for this retrospective study has not been received.

Peer-review: Externally peer-reviewed.

Conflict of Interest: No conflict of interest was declared by the authors.

Financial Disclosure: The authors declared that this study has received no financial support.

\section{References}

1. World Health Organization.World Report on Violence and Health. Geneva, Switzerland: World Health Organization; 2002. Available at: http://apps. who.int/iris/bitstream/10665/42495/1/9241545615_eng.pdf. Accessed February 21, 2016.

2. Pinheiro PS. World Report on Violence Against Children. United Nations Secretary-General's Study on Violence Against Children. 2006. Available at: http://www.unviolencestudy.org. Accessed February 21, 2016.

3. Keenan HT, Runyan DK, Marshall SW, Nocera MA, Merten DF, Sinal SH. A population-based study of inflicted traumatic brain injury in young children. JAMA 2003; 290: 621-6. [CrossRef]
4. Gilbert R, Kemp A, Thoburn J, Sidebotham P, Radford R, Glaser D, et al. Child maltreatment 2. Recognizing and responding to child maltreatment. Lancet 2000; 373: 167-80. [CrossRef]

5. Runyan DK, ShankarV, Hassan F, Hunter WM, Jain D, Paula CS, et al. International variations in harsh child discipline. Pediatrics 2010; 126: e701-11. [CrossRef]

6. Agirtan CA, Akar T, Akbas S, Akdur R, Aydin C, Aytar G, et al. Establishment of interdisciplinary child protection teams in Turkey 2002-2006: identifying the strongest link can make a difference! Child Abuse Negl 2009; 33: 247-55. [CrossRef]

7. Oral R, Can D, Kaplan S, Polat S, Ates N, Cetin G, et al. Child abuse in Turkey: an experience in overcoming denial and a description of 50 cases. Child Abuse Negl 2001; 25: 279-90. [CrossRef]

8. Demirli Çaylan N, Yılmaz G, Oral R, Karacan CD, Zorlu P. Abusive head trauma: report of 3 cases. Ulus Travma Acil Cerrahi Derg 2013; 19: 261-6. [CrossRef]

9. Oral R, Yagmur F, Nashelsky M, Turkmen M, Kirby P. Fatal abusive head trauma cases: consequence of medical staff missing milder forms of physical abuse. Pediatr Emerg Care 2008; 24: 816-21. [CrossRef]

10. Koç F, Akşit S, Turhan T, Erşahin $Y$, Tomba A, Halıcıoğlu O, et al. Shaken baby syndrome: case report. Turkiye Klinikleri J Med Sci 2012; 32: 1781-5. [CrossRef]

11. Yagmur F, Asil H, Per H, Aslan D, Coskun A. Shaken baby syndrome and 3 cases. Adli Tıp Dergisi 2010; 24: 42-9.

12. Beyaztas FY, Dokgoz H, Oral R, Demirel Y. Child physical abuse: a five case report. Middle East Journal of Family Medicine 2006; 4: 21-6.

13. Duhaime AC, Alario AJ, Lewander WJ, Schut L, Sutton LN, Seidl TS, et al. Head injury in very young children: mechanisms, injury types, and ophthalmologic findings in 100 hospitalized patients younger than 2 years of age. Pediatrics 1992; 90: 179-85.

14. Brown J, Cohen P, Johnson JG, Salzinger S. A longitudinal analysis of risk factors for child maltreatment: Findings of a 17-year prospective study of officially recorded and self-reported child abuse and neglect. Child Abuse Negl 1998; 11: 1065-78. [CrossRef]

15. Sieswerda-Hoogendoorn T, Bilo RA, van Duurling LL, Karst WA, Maaskant $J M$, van Aalderen WM, et al. Abusive head trauma in young children in the Netherlands: evidence for multiple incidents of abuse. Acta Paediatr 2013; 102: e497-501. [CrossRef]

16. Gumbs GR, Keenan HT, Sevick CJ, Conlin AM, Lloyd DW, Runyan DK, et al. Infant abusive head trauma in a military cohort. Pediatrics 2013; 132: 668-76. [CrossRef]

17. Hennes H, Kini N, Palusci VJ. The epidemiology, clinical characteristics and public health implications of shaken baby syndrome. In Lazoritz S, Palusci VJ (Eds.), The shaken baby syndrome: A multidisciplinary approach., The Haworth Maltreatment and Trauma Press, Binghamton 2001. pp. 19-40. [CrossRef]

18. Barr RG. Preventing abusive head trauma resulting from a failure of normal interaction between infants and their caregivers. Proc Natl Acad Sci U S A 2012; 109: 17294-301. [CrossRef]

19. Jenny C, Hymel KP, Ritzen A, Reinert SE, Hay TC. Analysis of missed cases of abusive head trauma. JAMA 1999; 281: 621-6. [CrossRef]

20. Forbes BJ, Rubin SE, Margolin E, Levin AV. Evaluation and management of retinal hemorrhages in infants with and without abusive head trauma. $J$ AAPOS 2010; 14: 267-73. [CrossRef]

21. Keenan HT, Runyan DK, Marshall SW, Nocera MA, Merten DF. A population-based comparison of clinical and outcome characteristics of young children with serious inflicted and noninflicted traumatic brain injury. Pediatrics 2004; 114: 633-9. [CrossRef]

22. Morad Y, Kim YM, Mian M, Huyer D, Capra L, Levin AV. Nonophthalmologist accuracy in diagnosing retinal hemorrhages in the shaken baby syndrome. J Pediatr 2003; 142: 431-4. [CrossRef]

23. Levin AV. Retinal hemorrhage in abusive head trauma. Pediatrics 2010; 126: 961-70. [CrossRef]

24. Piteau SJ, Ward MG, Barrowman NJ, Plint AC. Clinical and radiographic characteristics associated with abusive and nonabusive head trauma: a systematic review. Pediatrics 2012; 130: 315-23. [CrossRef]

25. Karakuş A, Can Öi, Dalgıç M, Olgun EG, Şen F, Yavuz IC. Medicolegal approach to child physical abuse in an emergency clinic. Eurasian J Emerg Med 2015; 14: 201-3. [CrossRef]

26. Yalcın SS. Abusive head trauma: the place in scientific papers. Çocuk Sağlığı ve Hastalıkları Dergisi 2011; 54: 227-30. 